\title{
Determination of Segari Rock Slope Excavation Technique using Geological Strength Index (GSI)
}

\author{
R Roslan ${ }^{1}$, RC Omar ${ }^{2}$,I.N.Z. Baharuddin ${ }^{3}$,Hairin Taha ${ }^{4}$, M.M.Fared ${ }^{5}$ and W.N.S.W.Hashim ${ }^{6}$ \\ 1,2,3,4, Institute of Energy Infrastructure, Universiti Tenaga Nasional, 43000, Kajang, Malaysia. \\ ${ }^{5,6}$ Maintenance Technical Expert and Performance, Grid Maintenance Department, Grid Division, TNB, Kuala Lumpur, Malaysia \\ *Corresponding author E-mail: rasyikin@uniten.edu.my
}

\begin{abstract}
Segari - Ayer Tawar rock materials were generally characterized as slightly weathered (Grade II) to moderately weathered (Grade III). Laboratory tests such as Brazilian tensile strength and point load strength index including direct shear strength were carried out using collected weathering sample from borehole to assess the rock strength. Hence, index testing was used to predict geological strength index, rock failure criterion from Hoek-Brown and deformation modulus mainly for the classification of rock mass engineering properties. The relationship between the uniaxial compressive strength and geological strength index of rocks were used in proposing suitable methods for cutting the rock slope.
\end{abstract}

Keywords: Engineering Properties; Granite; Rock Strength; Uniaxial Compressive Strength; Geological Strength Index.

\section{Introduction}

Assessment of engineering properties for soils and rocks are the main activities undertaken in the planning and implementation of the physical land use for the development or engineering project in the areas. The assessment is conducted to identify the suitability of the sites and earth materials as a building material and to design appropriate structures. However, the main test is to determine the basic characteristics including soil and rock strength which needs to be carried out appropriately following specific requirements for a particular kind of development because such tests are often limited by time and budget. Thus, the assessment of the engineering properties of the soils and rock for other purposes requires additional analysis based on the information and existing test results. Further analysis is very important because the tests conducted, especially in the laboratory, involves only intact rock properties that are not affected by any discontinuities such as joints and fractures. Instead, the nature of the rock mass is very different from the results of laboratory tests for the existing discontinuity influence.

UNITEN has conducted the study for the determination of engineering properties of rock sample for slope stability assessment in the area of Segari -Ayer Tawar, Perak. This study involved four (4) borehole boring activities for sampling and laboratory testing of soil and rock engineering properties. The study area was covered by residual soil with variable thickness, overlay on top of medium to coarse grain biotite granite bedrock. The depth of granite sample from different slope location of the boreholes was in the range between $4.5 \mathrm{~m}$ to $7.5 \mathrm{~m}$. The borehole samples showed that the variation of rock quality designation (RQD) varied from $41 \%$ to $86 \%$. The experimental result from the borehole samples was used to identify the direct shear test, Brazilian test, point load test and uniaxial compression test. From these laboratory results, the characteristics or engineering properties and their indexes were estimated based on predictive judgement method through site observations and justification. Next, the correlation of the engineering properties was used to suggest the workability method for the excavation technique of the slope for conceptual design.

\section{Objectives}

The observation and testing of the engineering properties of rock material in the laboratory were analyzed to estimate some of the engineering properties of rock masses following the guidelines in the ISRM standard [1]. This paper presents the results of the laboratory analysis and the simulation using RocLab1 and RMI calculation using Hoek - Brown Rock Criterion. Based on the integration from the analysis of uniaxial compressive strength for intact rocks versus geological compressive strength, a suitable method of cutting rock slope at the study area was proposed in the final part of the paper.

\section{Methodology}

Rock samples from borehole coring were tested in the laboratory for the determination of engineering properties using the uniaxial compressive strength, Brazilian tensile strength, and point load strength index as well as direct shear strength using suggested methods by [2], [3], [4] \& [5]. The rock density and water content was also determined in the laboratory. Besides laboratory tests, evaluation of the physical properties was also made based on the observation of the samples and the rocks at the site. Through this method, the degree of weathering of rocks and Rock Quality Designation (RQD) were determined. Further analysis of the engineering properties result were carried out using the concepts and approaches developed by [6], [7] and [8]. Based on these assessment, other characteristics were determined as geological strength index, rock failure criterion from Hoek-Brown and 
deformation modulus. The method of cutting the rock slope for the proposed study area based on common methods used was influenced by the relationship between the uniaxial compressive strength and geological strength index of rock.

\section{Results}

The Segari-Ayer Tawar rock quality was identified as poor to very good quality with grade of weathering as grade II and grade III. The Brazilian (indirect tensile) test showed the highest value which was $13.5 \mathrm{MPa}$ and the lowest value of Brazilian test was 2.5 $\mathrm{MPa}$. These values depend on the depth and the weathering grade that was influenced by the discontinuity. The point load test gave the result of 2.0 MPa, being the lowest and $10.41 \mathrm{MPa}$, being the highest. The loading of $19.5 \mathrm{MPa}$ to $98.8 \mathrm{MPa}$ were the uniaxial compression load that the rock in this area could retain before it fails.

This indicates a good sign of a moderate to good quality of rock. The direct shear test result gave the values of friction angles and cohesion values of 5 to 20 degrees and 0 to $3.1 \mathrm{MPa}$, respectively. Table 1.0 shows the physical and engineering properties of the rock samples in the selected area surrounding the Segari-Ayer Tawar. While, Figure 1 shows the example of borehole core from Segari-Ayer Tawar study area.

Table 1: Physical and engineering properties of rock samples

\begin{tabular}{|c|c|c|c|c|}
\hline No. Borehole & BH1 T5A & BH1 T6A & BH1 T15A & $\mathrm{BH} 2 \mathrm{~T} 15 \mathrm{C}$ \\
\hline The depth of rock samples (m) & $\begin{array}{c}12.5- \\
17.0 \\
\end{array}$ & $\begin{array}{c}11.5- \\
16.5\end{array}$ & $1.0-5.5$ & $3.3-8.3$ \\
\hline Weathering Grade & $\|$ & $\|$ & $\|\cdot\| \|$ & $\|\cdot\|$ \\
\hline Rock Quality Designation, RQD (\%) & $80-90$ & $44-100$ & $41-68$ & $75-86$ \\
\hline Rock Density, $\rho\left(\mathrm{g} / \mathrm{cm}^{3}\right)$ & 2.59 & 2.62 & 2.56 & 2.52 \\
\hline Brazillan Tensile Strength (MPa) & $3.9-13.5$ & $9.7-13.1$ & $6.4-13.1$ & $2.5-6.3$ \\
\hline Point Load Strength Index, Is50 & $6.8-10.4$ & $3.8-8.8$ & 8.4 & $2.0-3.3$ \\
\hline Uniaxial Compressive Strength, $\sigma_{a i}(\mathrm{MPa})$ & $\begin{array}{c}35.6- \\
98.8\end{array}$ & $\begin{array}{c}62.8- \\
89.9\end{array}$ & $\begin{array}{c}44.8- \\
75.3\end{array}$ & $\begin{array}{l}19.5- \\
22.3\end{array}$ \\
\hline \multicolumn{5}{|l|}{ Shear Strength: } \\
\hline Cohesion, C (MPa) & 1.2 & 0 & 1.6 & 3.1 \\
\hline Friction Angle, $\phi\left(0^{\circ}\right)$ & 11 & 20 & 5 & 5 \\
\hline
\end{tabular}

\subsection{Geological Strength Index}

Observations of the rock samples from the study area showed that the rocks were characterized as slightly weathered (Grade II) to moderately weathered (Grade III). Rock materials especially near the fractures surface have undergone a slight change of color, and more significant changes in the rocks weathered Grade III. There were between two and three sets of fractures that may affect in reducing the strength of the rock masses and activate the weathering process of rocks. Further observation showed that the fractures surface was mainly filled with silica and clay due to partially changes during weathering process. Based on the characterization of the rock masses by [9], [10], and [11], the rocks at the study area were estimated to have geological strength (GSI) index between 60 and 70 (Figure 2).

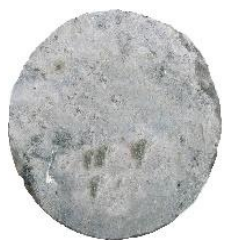

(a)Plan View

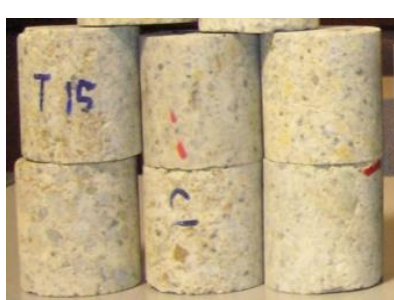

(b) Side View

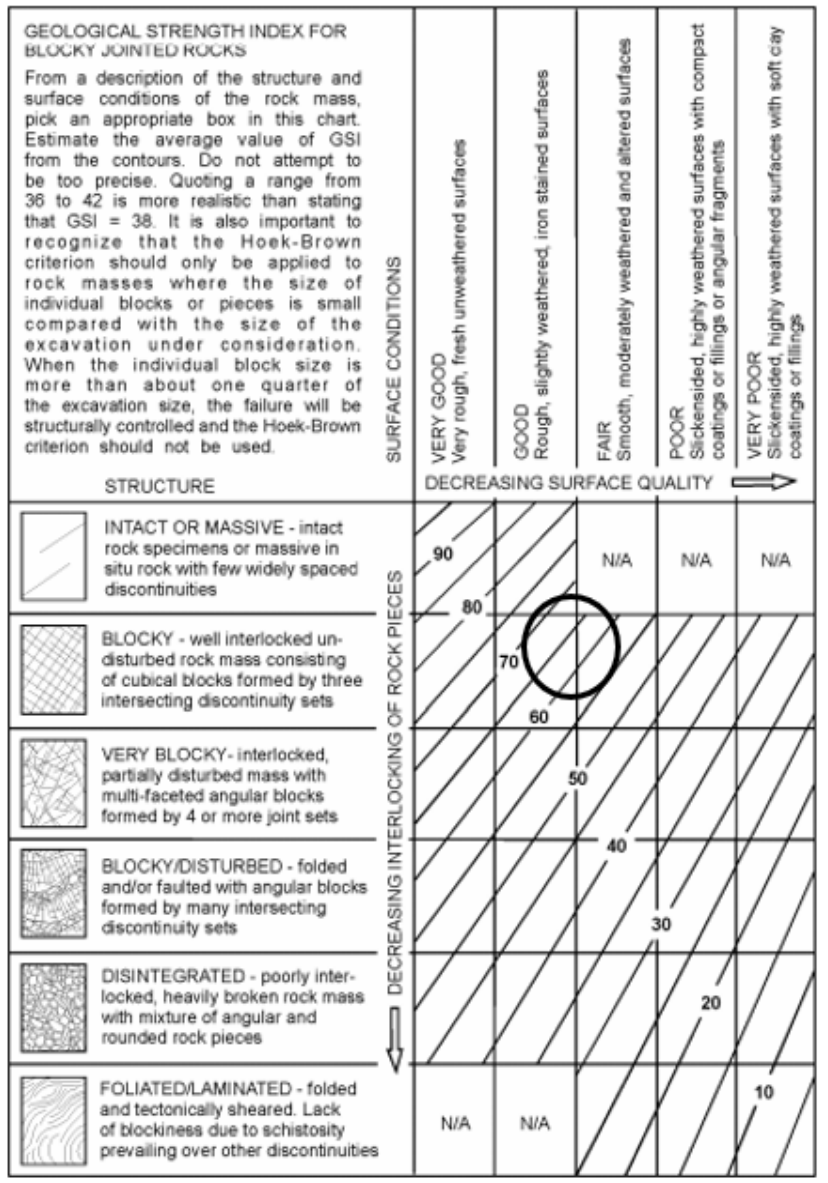

Fig. 2: Geological strength index estimates from the geological observations (general chart from [12])

\subsection{Rock Engineering Properties}

Laboratory tests on rock samples provide the engineering properties of intact rock that is not affected by any discontinuity. The results of the tests are listed in Table 1. The uniaxial compressive strength of the rock samples was generally between 50 and $100 \mathrm{MPa}$. This shows that the engineering properties of the rocks were characterized as slightly weathered to moderately weathered. Rock strength becomes lower when the rock materials change slightly due to weathering process. The physical and other engineering properties of the rock materials are generally higher for slightly weathered compared moderately weathered of rocks.

\subsection{Hoek - Brown Rock Failure Criterion}

The generalized Hoek-Brown failure criterion for jointed rock masses such as fractures is expressed as:

$\sigma_{1}^{b}=\sigma_{a}^{b}+\sigma_{e i}\left(m_{b} \frac{\sigma_{i}^{p}}{\sigma_{s i p}}+s\right)^{a}$

Where $\sigma 1$ and $\sigma 3$ are the maximum and minimum effective stresses at failure respectively, $\mathrm{mb}$ is the value of the Hoek-Brown constant for rock mass, $s$ and a are constants which depend upon the characteristics of the rock mass, and $\sigma_{\mathrm{ci}}$ is the uniaxial compressive strength of the intact rock material.

Usually the intact rock material is determined based on tests of rock samples, defined by the equation:

$\sigma_{1}^{b}=\sigma_{a}^{b}+\sigma_{c i}\left(m_{i} \frac{\sigma_{a}^{p}}{\sigma_{c i}}+1\right)^{0.5}$

Fig. 1: Rock coring samples from BH15 Segari-Ayer Tawar 
By obtaining the $\sigma_{\mathrm{ci}}$ value and estimates the GSI value as well as $\mathrm{m}_{\mathrm{i}}$ value, the equation above can be solved to determine the stresses that cause failure of rock [12]. The value of $m_{i}$ is given the choice of the stress range for this curve fitting process as shown below (Figure 3):

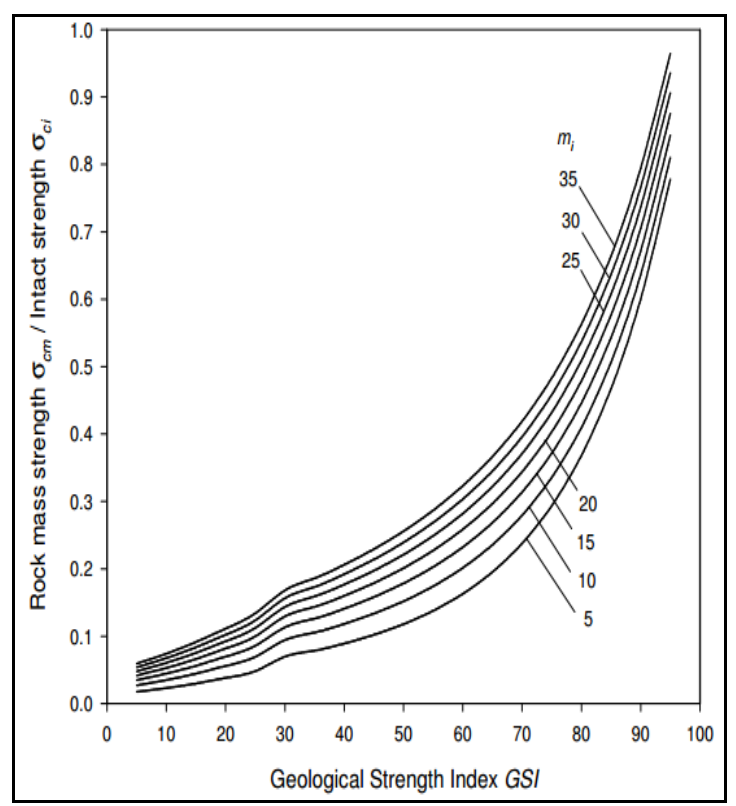

Fig. 3: Ratio of uniaxial compressive strength of rock mass to intact rock versus geological strength index, GSI [12]

\subsection{Deformation Modulus}

Besides of rock mass strength, the deformation modulus of rock is also an important input for analysing the rock properties to determine the stability of the site and designing engineering structures. In test facilities with limited conditions, deformation modulus can be estimated by the uniaxial compressive strength for intact rocks, $\sigma_{\mathrm{ci}}$ and the geological strength index, GSI using the following equation:

$$
E_{m}=\sqrt{\frac{\sigma_{c i}}{100}} 10\left(\frac{G S I-10}{40}\right)
$$

This equation has been simplified to relationship series curves of deformation modulus and geological strength index for several of uniaxial compressive strength as shown in Figure 4. Based on Figure 4, uniaxial compressive strength with $20 \mathrm{MPa}$ and $90 \mathrm{MPa}$ and geological strength index with 60 and 70, the deformation modulus of rock masses at the study area was estimated between 10 and $20 \mathrm{GPa}$. The dotted line shown in Figure 4 represents the deformation modulus of rock masses in the study area.

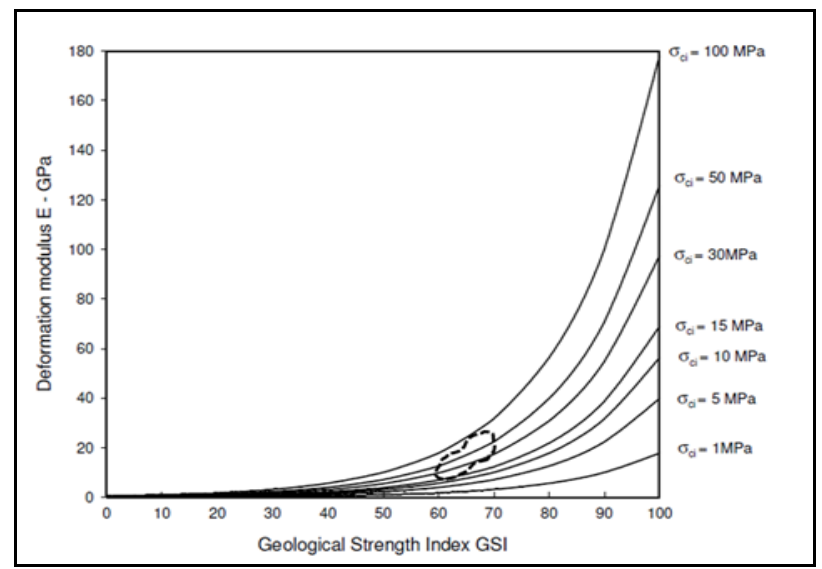

Fig. 4: Deformation modulus, E versus geological strength index, GS (standard graph as [12])

\subsection{Rock Mass Strength Analysis using RocLab}

RocLab is a software program for the determination of rock mass strength parameters, using Hoek-Brown failure criterion. The geological strength index, GSI and data from Table 1 were analysed by RocLab and the details of the results are illustrated in Figure 5 and 6 . The analysis using RocLab is mainly for the comparison of results with the overlay predictive and method as discussed in the previous section. This analysis showed that the modulus of deformation of Segari-Ayer Tawar rock was slightly similar to overlay predictive method which was $10.899 \mathrm{GPa}$.

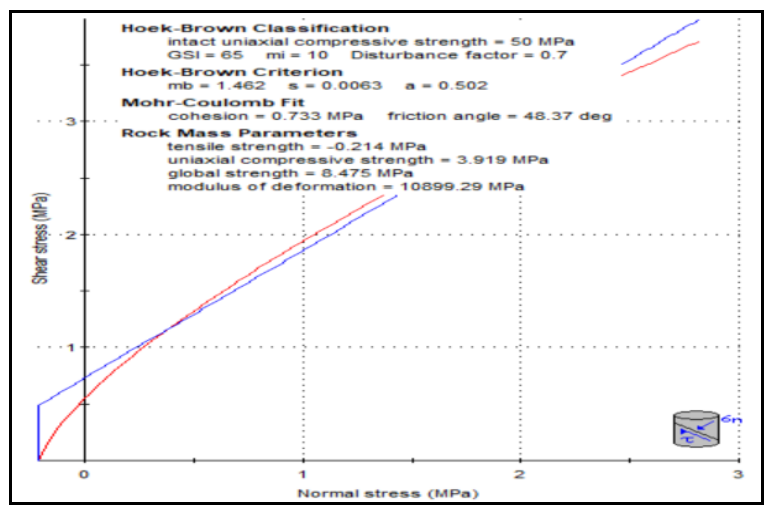

Fig. 5: Analysis of rock strength using RocLab for Segari-Ayer Tawar

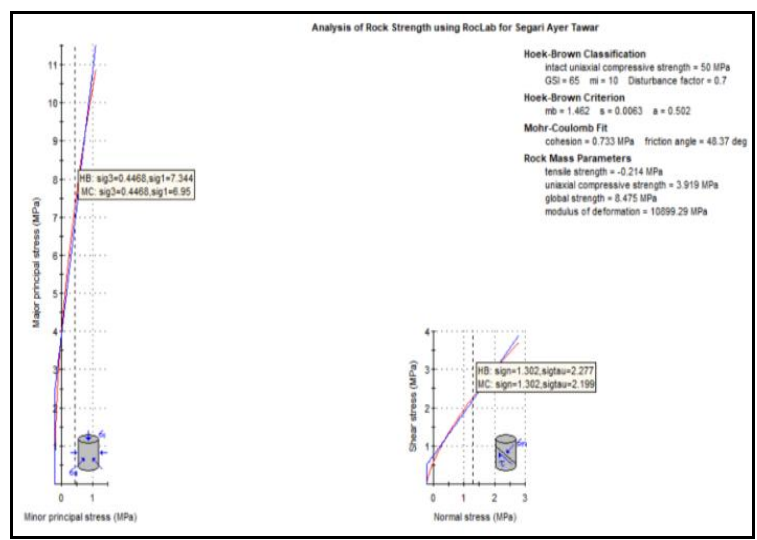

Fig. 6: Analysis shows minor and major stress of Segari Ayer Tawar using RocLab.

\subsection{Cutting Slopes Method}

The relationship between uniaxial compressive strength of intact rocks, $\sigma_{\mathrm{ci}}$ and geological strength index, GSI as well as experience in excavation works and rock cutting can be used to propose a method of cutting rock slopes. The approach is using three (3) plots of features introduced by [11] and [12] as shown in Figure 7.

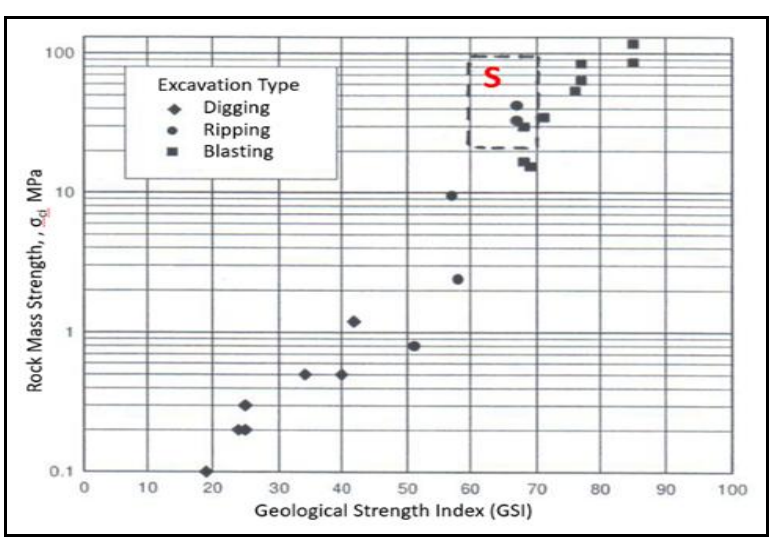

Fig. 7: Plot of uniaxial compressive strength for intact rocks versus geological compressive strength for several methods of cutting rock slopes. 
Figure 7 suggests three (3) common methods for the excavation works or cutting rock slopes which depends on two (2) parameters as stated. Based on the value of $\sigma_{\mathrm{ci}}$ and estimation of GSI for the study area, it was found the suitable excavation process in that particular sample area labelled as $\mathrm{S}$ to be carried out with blasting and ripping.

\section{Conclusion}

Further assessments from the results of the laboratory tests for engineering properties of the rock materials at the study area provide the estimate for several engineering properties of rock masses. For that purpose, the values of uniaxial compressive strength for rock materials and the estimated geological strength index for rock masses are important as a main input. It would be preferable if it were any other strength properties of rock materials which are determined from the laboratory tests can be used to estimate the characteristics of rock masses.

This study applied the general relationship between several of main parameters that have been proven by other researchers. However, tests of the engineering properties for rock masses need to be conducted at the site to verify the results of the analysis because the characteristics of the rock mass is strongly influenced by the real conditions on the site.

\section{Acknowledgement}

Authors wish to acknowledge assistance from research engineer, post graduate students and technician for the supports. The authors also would like to extend their gratitude to financial support from UNITEN R\&D under U-TS-CR-17-01grant.

\section{References}

[1] Reşat Ulusay (2014). The ISRM Suggested Methods for Rock Characterization, Testing and Monitoring, 2007-2014. 2015, $280 \mathrm{p}$. 70, Elsevier.

[2] Brown, E.T. (1981). Rock characterization Testing and Monitoring ISRM Suggested Method. Pergamon Press: Oxford.

[3] Nazir, R., Momeni, E., Armaghani, D.J., and Mohd Amin, M.F. (2013). Correlation between unconfined compressive strength and indirect tensile strength of limestone rock samples. Electronic Journal of Geotechnical Engineering, vol. 18, no. 1. pp. 1737-1746.

[4] Karaman, K., KesimaL, A., and Ersoy, H. (2014). A comparative assessment of indirect methods for estimating the uniaxial compressive and tensile strength of rocks. Arabian Journal of Geosciences. DOI 10.1007/s12517-014-1384-0

[5] Abigail Hackston and Ernest Rutter (2016). The Mohr-Coulomb criterion for intact rock strength and friction - a re-evaluation and consideration of failure under polyaxial stresses. Solid Earth, 7, 493-508, www.solid-earth.net/7/493/2016/ doi:10.5194/se-7-4932016

[6] Hoek, E. (1998). Reliability of Hoek-Brown estimates of rock mass properties and their impact on design. Technical Note, Int. J. Rock Mech. Min. Sci. 35:63-68.

[7] Hoek, E. (1994). Strength of rock and rock masses. News J. ISRM 2 (2): 4-16.

[8] Hoek, E. \& Brown, E.T. 1997. Practical estimates of rock mass strength. Int. J. Rock Mech. Min. Sci. 34: 1165-1186.

[9] Hoek E (2007) Practical Rock Engineering. e-book

[10] Marinos V, Marinos P, Hoek E (2005) The geological strength index: applications and limitations. Bull Eng Geol Environ 64(1):55-65

[11] Erik Eberhardt (2012). The Hoek-Brown Failure Criterion. Rock Mech Rock Eng (2012) 45:981-988. DOI 10.1007/s00603-012 0276-4.

[12] Ayberk Kaya, Fikri Bulut and Selçuk Alemdag (2011) Applicability of excavatability classification systems in underground excavations: A case study. Scientific Research and Essays Vol. 6(25), pp. 5331-5341. DOI: 10.5897/SRE11.1343. ISSN 1992-2248, Academic Journals. 